\title{
The Impact of Age and Gender on Severity and Types of Periodontal Diseases among Patients from Two Regions in Saudi Arabia
}

\author{
Mohammed M. A. Abdullah Al-Abdaly ${ }^{1}$, Hussain Saad Hussain AlQahtani'2, \\ Sultan Saeed Hadi Al-Qahtani ${ }^{3}$ \\ ${ }^{1}$ Periodontics and Community Dental Sciences Department, College of Dentistry, King Khalid University, Abha, Saudi Arabia \\ ${ }^{2}$ Ministry of Health, Al-Wajh, Saudi Arabia \\ ${ }^{3}$ College of Dentistry, King Khalid University, Abha, Saudi Arabia \\ Email: *malabdaly20@gmail.com
}

How to cite this paper: Al-Abdaly, M.M.A.A., AlQahtani, H.S.H. and AlQahtani, S.S.H. (2019) The Impact of Age and Gender on Severity and Types of Periodontal Diseases among Patients from Two Regions in Saudi Arabia. Open Journal of Stomatology, 9, 39-50.

https://doi.org/10.4236/ojst.2019.93005

Received: January 25, 2019

Accepted: March 9, 2019

Published: March 12, 2019

Copyright $\odot 2019$ by author(s) and Scientific Research Publishing Inc. This work is licensed under the Creative Commons Attribution International License (CC BY 4.0).

http://creativecommons.org/licenses/by/4.0/

(c) (i) Open Access

\begin{abstract}
Background: Periodontitis is the predominant disease in the oral cavity and there are alterations in the periodontal tissues associated with the aging and gender of the patient. Objective: The present study was designed to assess the impact of age and gender of the patient on severity and types of periodontal diseases among patients from two regions in Saudi Arabia. Materials and Methods: The current study was done on 600 Saudi patients from Aseer and Tabuk regions in Saudi Arabia (50\% males and 50\% females) and divided into three equal groups $(n=200)$ according to the patients age: children and young patients ( 1 - 24 years old), adults patients ( 25 - 64 years old) and seniors patients (more than 65 years old). Plaque index (PLI), gingival index (GI), periodontal pocket depth (PPD) and clinical attachment loss (CAL) were recorded from all participants. The data were collected and analyzed with SPSS to determine the mean and standard deviation $( \pm S D)$ and the values of significance $(\mathrm{P} \leq 0.005)$. Results: The results of the present study revealed that 340 patients (56.7\%) were affected with gingivitis dental biofilm induced and 260 patients were affected by periodontitis. Gingivitis dental biofilm-induced is especially detected in children and young patients (33.3\%), adult patients (16.7\%) and seniors patients (6.7\%) whereas periodontitis cases were seen among the adult and seniors patients (16.7\%) and (26.6\%) respectively. Furthermore, the present study displayed the higher severity and prevalence of gingivitis dental biofilm-induced and periodontitis among females more than males in group II and group III maybe due to hormonal changes. The present study saw that there are statistically significant differences in clinical findings in the comparison between groups of this study $(\mathrm{P} \leq 0.005)$. Conclusion: We conclude that there is a relation between severity and types
\end{abstract}


of periodontal diseases and the ages and genders of Saudi patients in Aseer and Tabuk regions, Saudi Arabia.

\section{Keywords}

Aseer, Periodontal diseases, Tabuk, Saudi Arabia

\section{Introduction}

Periodontal diseases are destructive inflammatory diseases due to the effect of the microbial factor on the tooth surfaces, and maybe cause permanent loss of supporting tissues and loss of the tooth in the end [1]. The clinical findings that are used to evaluate the severity of periodontal diseases include bleeding on probing, probing depth, and clinical attachment level [2].

Numerous studies have revealed that the microbial factors alone are not enough to occur periodontal attachment loss; consequently periodontal diseases are considered multi-factorial etiology [3]. Depending on the case description and the characteristics of the sample, the severity and extent of periodontal diseases increased with the progression of the age [4]. Consequently, the alterations in the periodontal structure related to the patient age reveal that progressing the age may be considered as a periodontal diseases risk factor [5]. The groups of the current study were designed as children and young patients, adult patients, and senior patient [6].

On the other hand, there is a relation between the prevalence of periodontal diseases and the variety of geography where the prevalence of periodontal diseases may increase in developing countries compared to the developed countries [7] [8]. The Egyptian study was the first study on the prevalence of periodontal diseases in the Arab region [9].

In Saudi Arabia, there is a clinical study on gingivitis dental biofilm induced prevalence and severity among the Saudi adult population [10]. Furthermore, longitudinal study displayed that there was a statistically significant correlation between the intensity of periodontal tissue destruction and the age of patients [11].

Other studies showed more destruction of periodontal tissues among men compared to the women [12]. The causes of these gender variations may be oral hygiene unawareness, which is popular among males [13]. Furthermore, periodontal diseases may appear among the women before menses and during ovulation due to a rise in progesterone level, which prevents the reconditioning of collagen fibers leading to blood vessels widening [14]. The lack of Estrogen decreases the density of bone in menopausal leading to loss of alveolar bone and finally teeth downfall [15].

There are many types of research carried out to evaluate the prevalence of periodontal diseases in Saudi Arabia. Nevertheless, the impact of age and gender on severity and types of periodontal diseases among patients did not carry out in 
Asser and Tabuk regions. Consequently, this study was designed to evaluate the relationship between the patients aging, gender, severity and types of periodontal diseases of Saudi patients into these two regions.

\section{Material and Methods}

The present study is a cross-sectional observational study carried out on 600 patients (50\% males and 50\% females) and selected from the outpatients dental clinics, college of dentistry, King Khalid University, Abha in Aseer region and outpatients dental clinics of Al-Wajh general hospital, Al-Nahdha primary health care center and Al-Fraea primary health care center in Tabuk region, Saudi Arabia. The current study included three equal age groups $(n=200)$ depended on the ages of patients, the severity and the prevalence of periodontal diseases as variable factors. The written form of participants' consents had been obtained according to the ethical approval form of the scientific research committee, college of dentistry, King Khalid University.

The age in the present study classified as follow; children and young patients ( 1 - 24 years old), adults' patients ( 25 - 64 years old) and seniors patients (more than 65 years old). Data had been collected in the period from October 2017 to April 2018 with total sampling as the sampling method and clinical examination in the same conditions. The variable dependent of this study is periodontal disease. Patient age and gender serves as the independent variable. All participants in the present study had not systemic diseases and not received periodontal treatment during the last 6 months before participation in this study.

The periodontal examination had been done to evaluate PLI [16], GI [17], PPD, and CAL and according to the clinical findings of periodontal examination, the participants classified as having mild, moderate and severe gingivitis dental biofilm-induced (Figure 1) and having stage I generalized periodontitis grade A, stage II generalized periodontitis grade $\mathrm{B}$ and stage III generalized periodontitis grade C (Figure 2 \& Figure 3) [18] [19] [20].

The clinical findings were collected and analyzed by a statistical software program SPSS version 23 (Statistical Package for Social Sciences) and z-test test due to the sample size is greater than 30 to assess the mean \pm standard deviation,

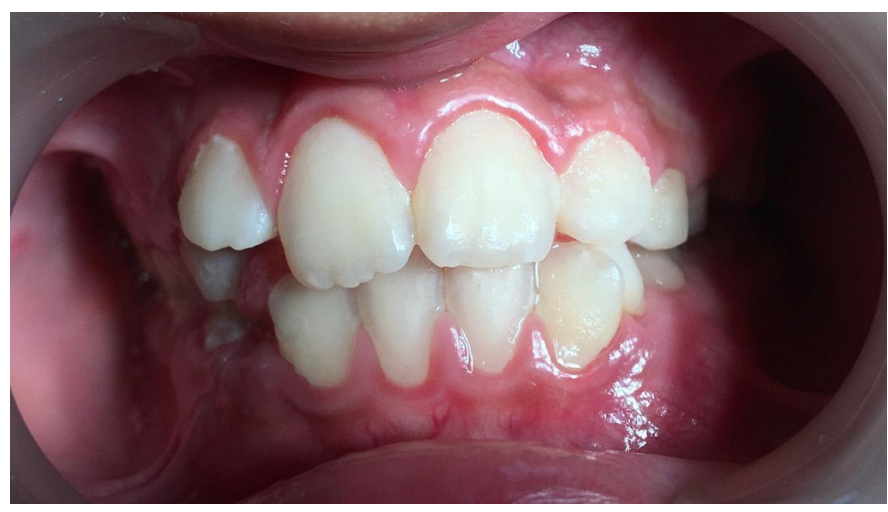

Figure 1. Clinical view of gingivitis dental biofilim-induced case in group I. 


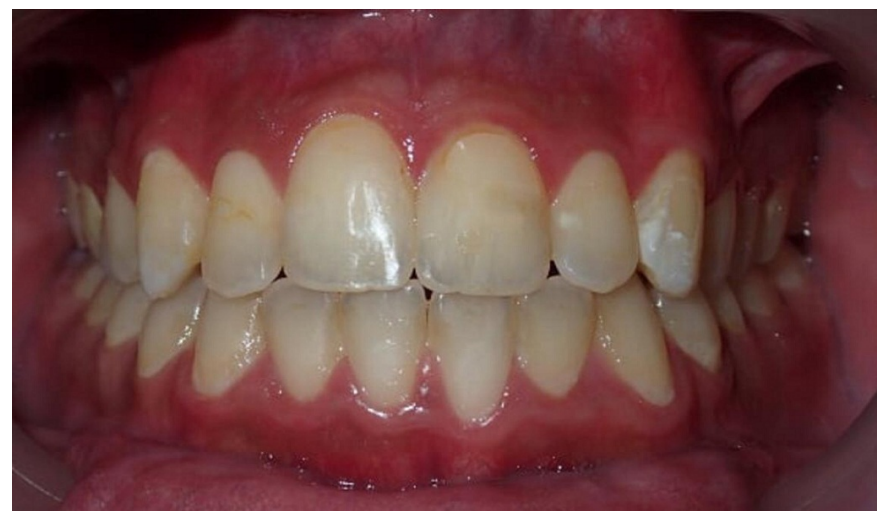

Figure 2. Clinical view of periodontitis case in group II.

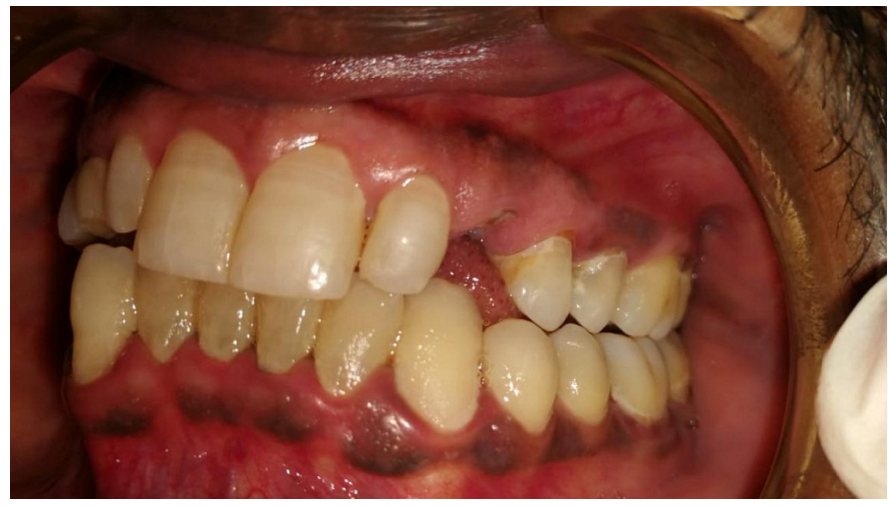

Figure 3. Clinical view of periodontitis case in group III.

comparison between the values of data and identify the values of significance ( $\mathrm{P}$ $\leq 0.05$ ) and finally statistical data were tabulated and graphed by using Microsoft-word 2010.

\section{Results}

The current study comprised 50\% female and 50\% male patients within three age groups. Table 1 and Figure 4 reveal the mean and standard deviation $( \pm \mathrm{SD})$ of age for both males and females patients in group I, II and III. The mean age of males in group I, II and III assessed as follows: $12.48 \pm 1.186,33.79 \pm 2.287$ and $55.35 \pm 4.121$ comparing with the mean age of females $11.61 \pm 0.921,30.42 \pm$ 2.081 and $52.77 \pm 3.312$. There is no significant statistical difference was seen between males and females in the present study, but there are statistical significant statistical differences in the mean of age was observed between the groups of the present study $(\mathrm{P}<0.005)$.

Table 2 and Figure 5 reveal the clinical periodontal parameters of the present study groups. There were differences detected between males and females according to PLI, GI, PPD and CAL scores. The mean PLI score of males in group I and group II was more than females, whereas in group III females has higher PLI scores when compared to males. The GI, PPD and CAL scores were higher in females than males in group II and group III when compared to groups I. 
Table 1. Mean and standard deviation $( \pm S D)$ of age.

\begin{tabular}{cccccccc}
\hline & \multicolumn{9}{c}{ Age } \\
Group & \multicolumn{2}{c}{ Mean } & \multicolumn{2}{c}{$\mathrm{N}^{* \star}$} & \multicolumn{2}{c}{ Std. Deviation } & \multirow{2}{*}{ P-Value } \\
\cline { 2 - 6 } & $\mathrm{M}^{\dagger}$ & $\mathrm{F}^{\dagger \dagger}$ & $\mathrm{M}^{\dagger}$ & $\mathrm{F}^{\dagger \dagger}$ & $\mathrm{M}^{\dagger}$ & $\mathrm{F}^{\dagger \dagger}$ & \\
\hline I & 12.48 & 11.61 & 100 & 100 & 1.186 & 0.921 & \\
II & 33.79 & 30.42 & 100 & 100 & 2.287 & 2.081 & $0.000^{\sharp}$ \\
III & 55.35 & 52.77 & 100 & 100 & 4.121 & 3.312 & \\
\hline
\end{tabular}

${ }^{*}$ Standard deviation. ${ }^{* *}$ Number; ${ }^{\dagger}$ Males; ${ }^{\dagger \dagger}$ Females; ${ }^{~}$ Significances differences $\mathrm{P}$ value $<0.05$.

Table 2. Mean $(\mathrm{M})$ and standard deviation $(\mathrm{SD} \pm)$ of periodontal parameter.

\begin{tabular}{|c|c|c|c|c|c|c|}
\hline & Group & Gender & $\mathrm{PLI}^{\ddagger}$ & $\mathrm{GI}^{9}$ & $\mathrm{PPD}^{\S}$ & $\mathrm{CAL}^{\mathrm{x}}$ \\
\hline \multirow{6}{*}{ I } & \multirow{2}{*}{ Mean } & Males & 0.89 & 0.87 & 1.76 & 0.86 \\
\hline & & Females & 0.77 & 082 & 1.22 & 0.82 \\
\hline & \multirow{2}{*}{$\mathrm{N}^{* *}$} & Males & 100 & 100 & 100 & 100 \\
\hline & & Females & 100 & 100 & 100 & 100 \\
\hline & \multirow{2}{*}{ Std. Deviation } & Males & 0.510 & 0.418 & 0.474 & 0.932 \\
\hline & & Females & 0.313 & 0.411 & 0.421 & 0.828 \\
\hline \multirow{6}{*}{ II } & \multirow{2}{*}{ Mean } & Males & 1.40 & 1.37 & 2.45 & 1.52 \\
\hline & & Females & 1.31 & 1.54 & 3.44 & 2.11 \\
\hline & \multirow{2}{*}{$\mathrm{N}$} & Males & 100 & 100 & 100 & 100 \\
\hline & & Females & 100 & 100 & 100 & 100 \\
\hline & \multirow{2}{*}{ Std. Deviation } & Males & 0.651 & 0.562 & 0.672 & 0.990 \\
\hline & & Females & 0.544 & 0.571 & 0.755 & 0.847 \\
\hline \multirow{6}{*}{ III } & \multirow{2}{*}{ Mean } & Males & 1.71 & 1.76 & 3.34 & 2.60 \\
\hline & & Females & 1.81 & 1.93 & 4.22 & 3.21 \\
\hline & \multirow{2}{*}{$\mathrm{N}$} & Males & 100 & 100 & 100 & 100 \\
\hline & & Females & 100 & 100 & 100 & 100 \\
\hline & \multirow{2}{*}{ Std. Deviation } & Males & 0.671 & 0.495 & 0.945 & 1.181 \\
\hline & & Females & 0.561 & 0.422 & 0.843 & 1.271 \\
\hline
\end{tabular}

${ }^{*}$ Standard deviation. ${ }^{*}$ Number. ${ }^{*}$ Plaque index. 'Gingival index. ${ }^{5}$ Periodontal pocket depth. ${ }^{x}$ Clinical attachment loss.

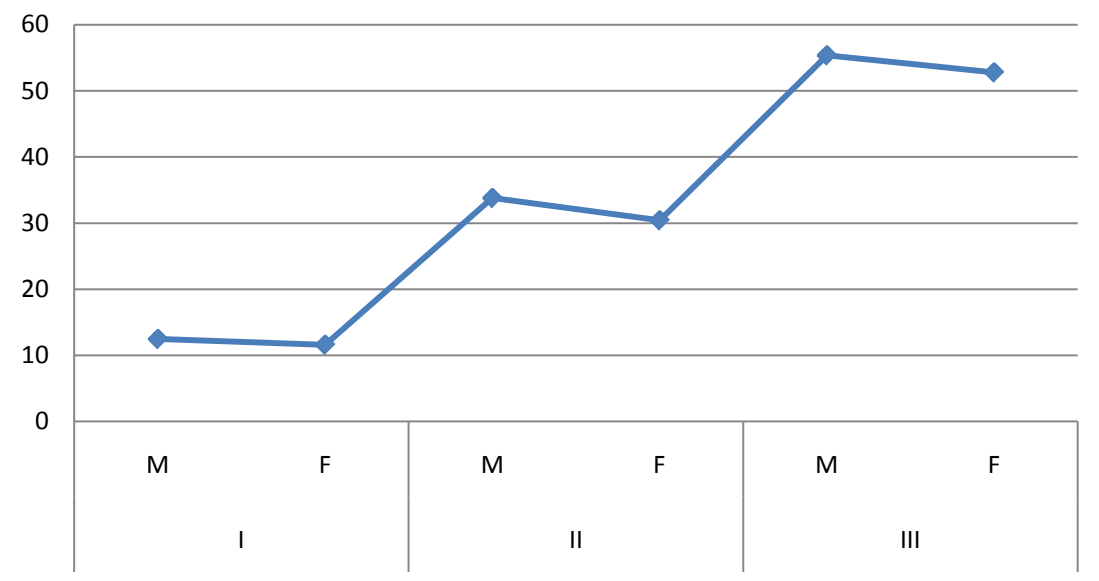

Figure 4. Mean comparison of age. 


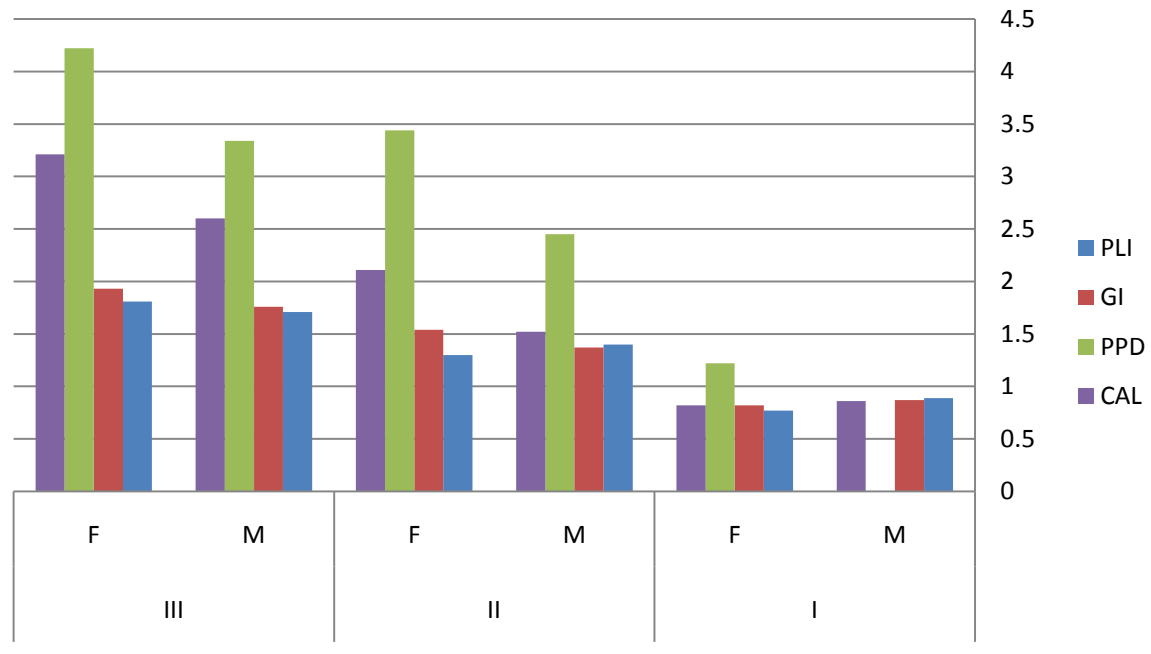

Figure 5. Mean comparison of periodontal parameter.

There were no statistically significant differences between males and females of the present study groups according to PLI, GI, PPD and CAL scores $(\mathrm{P}>0.005)$. The comparison between group I, group II and group III showed statistically significant differences in PLI, GI, PPD and CAL $(\mathrm{P}<0.005)$ (Table 3 ).

The results in Table 4 and Figure 6 exposed that the males in young patients group had mild and moderate gingivitis dental biofilm-induced (16.3\%) and (3.0\%) compared to (10\%) and (4.0\%) of females had mild and moderate gingivitis dental-biofilm induced whereas severe gingivitis dental biofilm-induced detected among the patients in group II and group III but it was more in females than males in both groups.

On the other hand, stage I generalized periodontitis grade A, stage II generalized periodontitis grade B and stage III generalized periodontitis grade $\mathrm{C}$ were distributed among males and females in group II and III only. Furthermore, the results of this study appeared that there is increased severity of periodontitis with increased the age moreover, the severity of periodontitis among females was more than males in group II and group III except mild form where it was more in males than females in both groups.

\section{Discussion}

Periodontal diseases predisposing factor is a factor which causes the development of periodontal destruction severity. In the current study, the impact of age and gender on severity and types of periodontal diseases assessed in a cross-sectional, observational study of 600 patients from two regions in Saudi Arabia. In several studies, there are variations of periodontal diseases types and severity according to the age group where gingival diseases are widespread among children and adolescence Chinese patients moreover, its severity increase with progression of the age [21].

The results of the present study reveal that gingivitis dental-biofilm induced, mild and moderate was predominantly in children and young patients' age group, 
Table 3. P-value of clinical findings.

\begin{tabular}{lccccc}
\hline & & CAL $^{x}$ & PPD $^{\$}$ & GI $^{9}$ & PLI $^{\ddagger}$ \\
\hline Group-1 & Males & & & \\
& Females & & & \\
Group-2 & Males & & & & \\
& Females & $0.001^{\#}$ & $0.001^{\#}$ & $0.001^{\#}$ & $0.001^{\#}$ \\
& Males & & & \\
Group-3 & Females & & & \\
& & & & \\
\hline
\end{tabular}

${ }^{*}$ Plaque index. 'Gingival index. ${ }^{5}$ Periodontal pocket depth. ${ }^{\times}$Clinical attachment loss. ${ }^{*}$ Significances differences $P$ value $<0.05$

Table 4. Distribution of periodontal diseases severity within group.

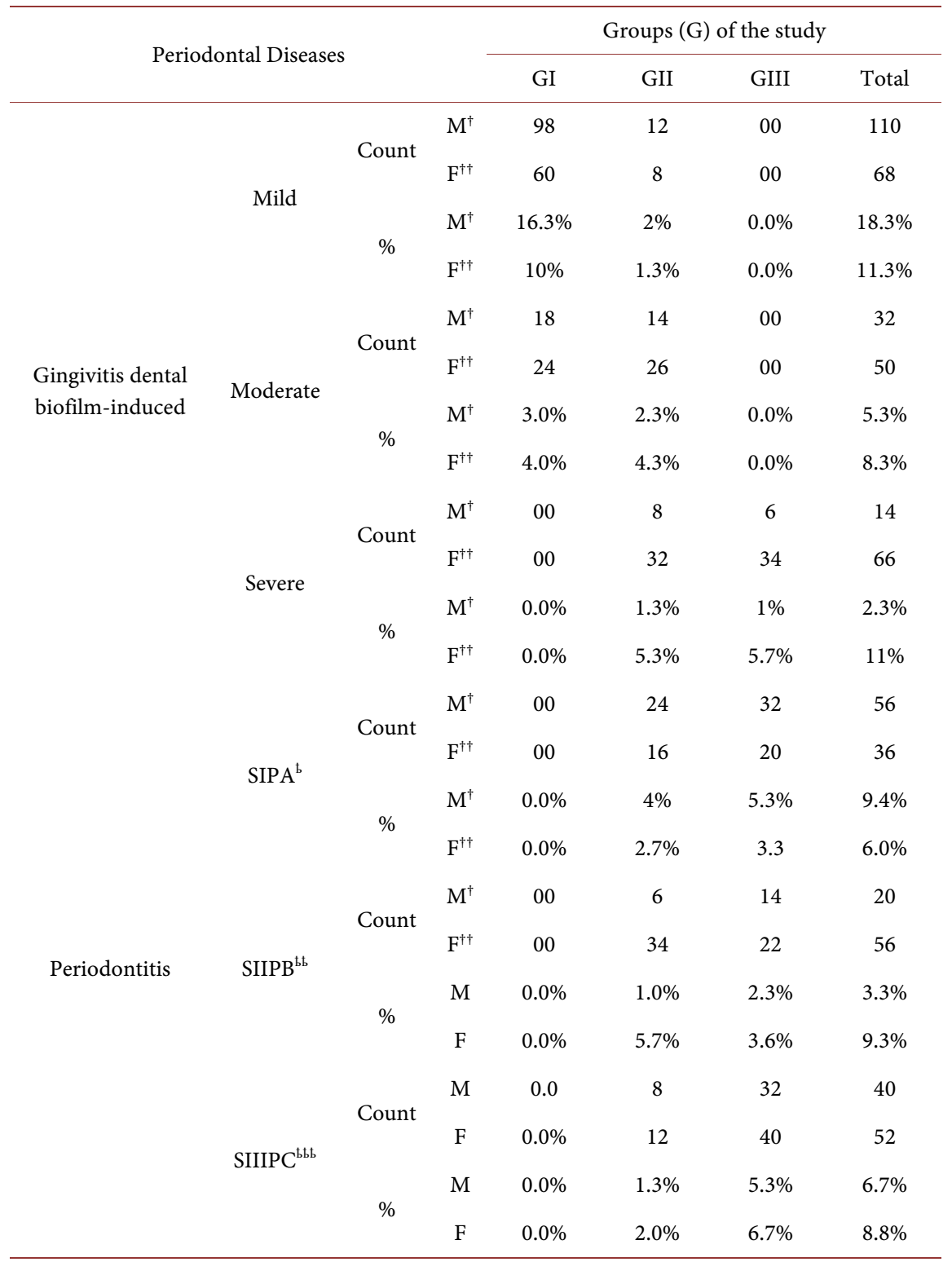

${ }^{\dagger}$ Males. ${ }^{\dagger \dagger}$ Females; ${ }^{\mathrm{b}}$ Stage I generalized periodontitis grade A; ${ }^{\mathrm{b}}$ Stage II generalized periodontitis grade $\mathrm{B}$; ${ }^{\mathrm{b}}$ Stage III generalized periodontitis grade C. 


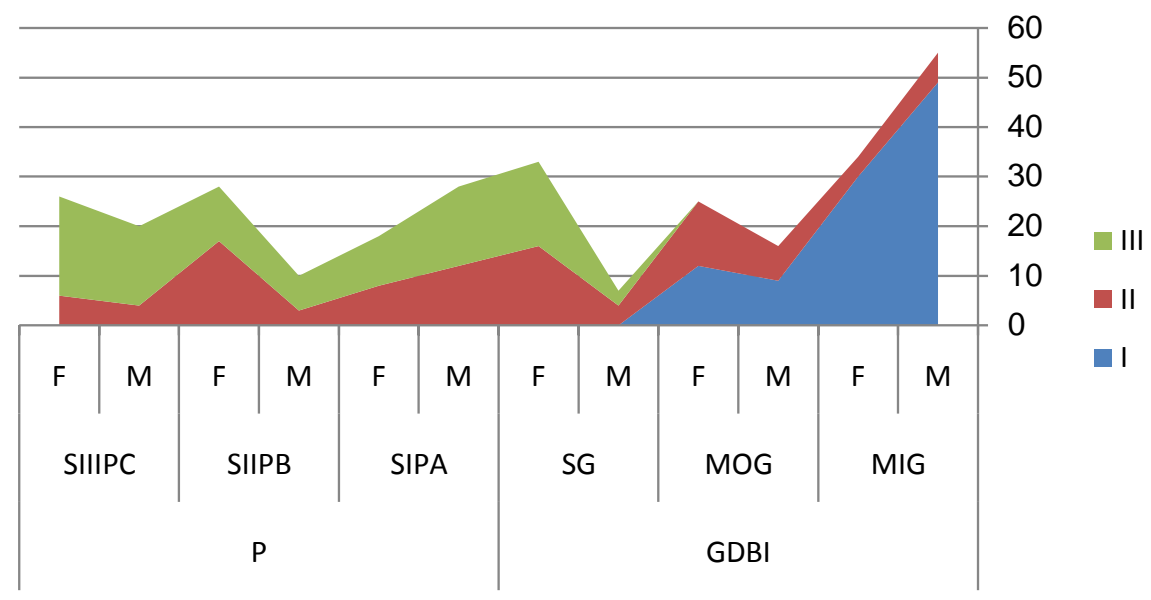

Figure 6. Distribution of periodontal diseases severity.

$16.3 \%$ and $3 \%$ in males. Moreover, $10 \%$ and $4 \%$ in females without severe gingivitis dental biofilm-induced among children and young patients' age group. From the present study also we found that severe gingivitis dental biofilm-induced was mostly among the patients of group II and group III and it was in females more than males. These clinical findings coinciding with the American study revealed that gingivitis dental biofilm-induced was existing in $95.7 \%$ of American adult patients [22].

The results of the present study displayed that there are variations in PLI and GI among male and female patients. We found that PLI was more in males compared with females in all groups except group III, whereas GI in females was more than males in group II and group III compared to group I also the clinical findings of the present study explore that there increase in PLI and GI with age progression. The clinical findings of the present study coincide with several past studies that displayed a link between the male gender and plaque formation. This may be due to the behavior, awareness of oral hygiene and visits to dental clinics which were less among males compared to females [8].

The researchers concluded that the periodontal diseases are fundamentally related to the status of the oral hygiene of patients and that the age and gender are associated and not etiologic factors [23]. So the existence of dental plaque in the present study is a tight relation to the being of gingival inflammation.

Probing pocket depth (PPD) and clinical attachment loss (CAL) are clinical signs for the development and severity of periodontitis [24]. The results of the present study displayed that there are differences in the mean of PPD and CAL in the comparison between males and females and a statistically significant difference in the comparison between group I, II and III. These results revealed that there is a negative impact of age and gender on the inflamed periodontal tissues. This result is consonant with several studies [25].

Periodontitis in the current study generally appeared in the adult patients age group (25 - 64 years old) (16.7\%) males and females, and seniors patients age group (more than 65 years old) (43.4\%) males and females. In agreement with 
the findings of Sheridan [26], Albert et al. [27], Novaes et al. [28] and Bridges et al. [29] studies where they revealed that the prevalence and the severity periodontal diseases increases with the progress of the patients' aging. Furthermore, These results are consistent with the clinical findings of Eke et al. [30] study that clarified increased spread of periodontal diseases among American adults and seniors patients and with the results of Nanaiah et al. [31] study, revealed that gingivitis dental biofilm-induced affected $1.5 \%$ of 1100 patients (15 - 18 years old). In the current study also this distribution of gingivitis dental biofilm-induced and periodontitis displays an increase of severity among females and seniors patients more than other patients. These results in agreement with the clinical findings of the previous studies where we found the progress of periodontal diseases severity is not caused by advancing the age but rather caused by hormonal alterations in females and an increase of plaque formation which is more in males than females in all age groups except group III [32].

In the end, the results of the current study demonstrated that there is the impact of gender and aging on oral hygiene status and plaque formation moreover severity and types of periodontal diseases. These results are consistent with studies which revealed that periodontitis and the severity of periodontal diseases are more among seniors' patients and females more than children and young patients and males as a result of the accumulative destruction of tissue through a life [33] [34].

The current study demonstrated that age and gender are possible etiologic factors of change periodontal diseases severity in Aseer and Tabuk regions, Saudi Arabia. These factors should be included in the diagnostic aids, to identify the types and severity of periodontal diseases. New methods of studies are necessary not only to distinguish other potential etiologic factors for periodontal diseases in Aseer region and Tabuk region but also to identify the effects of environmental, societal and lifestyle in these regions in Saudi Arabia on these possible factors and to evaluate their effects on the pathogenesis of periodontal diseases.

\section{Conclusion}

We conclude that periodontal diseases are fundamentally correlating with the status of patients' oral hygiene and the age and gender may be associated and not the etiologic factor. Moreover, an increase of periodontal destruction with a progression of the age may be attributed to the reduction of the immune system and the deterioration of periodontal tissue integrity.

\section{Strength and Limitations}

A strength of the current study, it was the first study to assess the effect of age and gender on severity and types of periodontal diseases among Saudi patients, especially in Aseer and Tabuk regions. The sample size was also appropriate. Regarding the limitations of the present study, there was difficulty in finding the different age groups in some hospitals, additionally, the lack of demographic in- 
formation for those Saudi people who did not participate in the study. Consequently, the assessment of age, gender, and periodontal disease was not uniformly distributed throughout Aseer and Tabuk regions. The results of this study need additional studies including more than two regions in Saudi Arabia to reveal the impact of age and gender on the types and severity of periodontal diseases in Saudi Arabia.

\section{Acknowledgements}

We would like to thank all the staff members in college of dentistry, King Khalid University and ministry of health, Tabuk region, Kingdom of Saudi Arabia, for their helping and supporting us in the present study to obtain preferable quality results.

\section{Conflicts of Interest}

There are no conflicts of interest.

\section{References}

[1] Socransky, S.S. and Haffagee, A.D. (1992) The Bacterial Etiology of Destructive Periodontal Disease: Current Concepts. Journal of Periodontology, 63, 322-331. https://doi.org/10.1902/jop.1992.63.4s.322

[2] Löe, H., Anerud, A., Boysen, H. and Morrison, E. (1986) Natural History of Periodontal Disease in Man. Rapid, Moderate and No Loss of Attachment in Sri Lankan Laborers 14 to 46 Years of Age. Journal of Clinical Periodontology, 13, 431-40.

[3] Griffiths, G.S., Wilton, J.M.A., Curtis, M.A., Maiden, M.F.J., Gillett, I.R., Wilson, D.T., et al. (1988) Detection of High-Risk Groups and Individuals for Periodontal Diseases. Clinical Assessment of the Periodontium. Journal of Clinical Periodontology, 15, 403-410. https://doi.org/10.1111/j.1600-051X.1988.tb01593.x

[4] Al-Harthi, L.S., Cullinan, M., Leichter, J.W., et al. (2013) Periodontitis among Adult Populations in the Arab World. International Dental Journal, 63, 7-11. https://doi.org/10.1111/idj.12002

[5] Huttner, E.A., Machado, D.C., de Oliveira, R.B., Antunes, A.G. and Hebling, E. (2009) Effects of Humanaging on Periodontal Tissues. Special Care in Dentistry, 29, 149-155. https://doi.org/10.1111/j.1754-4505.2009.00082.x

[6] Akbar, F.H. and Pratiwi, R. (2016) Patient Satisfaction against the Quality of Dental Health Services at Dental Polyclinic of Tenriawaru General Hospital in Bone Regency. Journal of Dentomaxillofacial Science, 1, 352-360.

[7] Petersen, P.E. and Ogawa, H. (2012) The Global Burden of Periodontal Disease towards Integration with Chronic Disease Prevention Andcontrol. Periodontology 2000, 60, 15-39. https://doi.org/10.1111/j.1600-0757.2011.00425.x

[8] Ababneh, K.T., Hwaij, Z.M. and Khader, Y.S. (2012) Prevalence and Risk Indicators of Gingivitis and Periodontitis in a Multi-Centre Study in North Jordan: A Cross Sectional Study. BMC Oral Health, 12, 1. https://doi.org/10.1186/1472-6831-12-1

[9] Dawson, C.E. (1948) Dental Defects and Periodontal Disease in Egypt, 1946-1947. Journal of Dental Research, 27, 512-523. https://doi.org/10.1177/00220345480270041201

[10] Idrees, M.M., Azzeghaiby, S.N., Hammad, M.M., et al. (2014) Prevalence and Sever- 
ity of Plaque-Induced Gingivitis in a Saudi Adult Population. Saudi Medical Journal, 35, 1373-1377.

[11] Haffajee, A., Socransky, S.S., Lindhe, J., Kent, R.L., Okamoto, H. and Yoneyama, T. (1991) Clinical Risk Indicators for Periodontal Attachment Loss. Journal of Clinical Periodontology, 18, 117-125. https://doi.org/10.1111/j.1600-051X.1991.tb01700.x

[12] Meisel, P., Reifenberger, J., Haase, R., Nauck, M., Bandt, C. and Kocher, T. (2008) Women Are Periodontally Healthier than Men, but Why Don't They Have More Teeth than Men? Menopause, 15, 270-275. https://doi.org/10.1097/gme.0b013e31811ece0a

[13] Mundt, T., Schwahn, C., Mack, F., et al. (2007) Risk Indicators for Missing Teeth in Working-Age Pomeranians-An Evaluation of High-Risk Populations. Journal of Public Health Dentistry, 67, 243-249. https://doi.org/10.1111/j.1752-7325.2007.00041.x

[14] Markou, E., Boura, E., Tsalikis, L., Deligianidis, A. and Konstantinidis, A. (2011) The Influence of Sex Hormones on Proinflammatory Cytokines in Gingiva of Periodontally Healthy Premenopausal Women. Journal of Periodontal Research, 46, 528-532.

[15] Grodstein, F., Colditz, G.A. and Stampfer, M.J. (1996) Post-Menopausal Hormone Use and Tooth Loss: A Prospective Study. The Journal of the American Dental Association, 127, 370-377. https://doi.org/10.14219/jada.archive.1996.0208

[16] Silness, J. and Loe, H. (1964) Periodontal Disease in Pregnancy II. Correlation between Oral Hygiene and Periodontal Condition. Acta Odontologica Scandinavica, 22, 122-135. https://doi.org/10.3109/00016356408993968

[17] Loe, H. and Silness, J. (1963) Periodontal Disease in Pregnancy I. Prevalence and Severity. Acta Odontologica Scandinavica, 2, 533-551. https://doi.org/10.3109/00016356309011240

[18] Chapple, I.L.C., Mealey, B.L., et al. (2018) Periodontal Health and Gingival Diseases and Conditions on an Intact and a Reduced Periodontium. Consensus Report of Workgroup 1 of the 2017 World Workshop on the Classification of Periodontal and Peri-Implant Diseases and Conditions. Journal of Clinical Periodontology, 45, S68-S77. https://doi.org/10.1111/jcpe.12940

[19] Caton, J., Armitage, G., Berglundh, T., et al. (2018) A New Classification Scheme for Periodontal and Periimplant Diseases and Conditions-Introduction and Key Changes from the 1999 Classification. Journal of Clinical Periodontology, 45, S1-S8.

[20] Papapanou, P.N., Sanz, M., et al. (2018) Periodontitis. Consensus Report of Workgroup 2 of the 2017 World Workshop on the Classification of Periodontal and Peri-Implant Diseases and Conditions. Journal of Clinical Periodontology, 45, S162-S170. https://doi.org/10.1111/jcpe.12946

[21] Zhang, J., Xuan, D., Fan, W., et al. (2010) Severity and Prevalence of Plaque-Induced Gingivitis in the Chinese Population. Compendium of Continuing Education in Dentistry, 31, 624-629.

[22] Li, Y., Lee, S., Hujoel, P., Su, M., Zhang, W., Kim, J., et al. (2010) Prevalence and Severity of Gingivitis in American Adults. American Journal of Dentistry, 23, 9-13.

[23] Abdellatif, H.M. and Burt, B.A. (1987) An Epidemiological Investigation into the Relative Importance of Age and Oral Hygiene Status as Determinants of Periodontitis. Journal of Dental Research, 66, 13-18. https://doi.org/10.1177/00220345870660010201

[24] Renvert, S., Dahlén, G. and Wikströn, M. (1998) The Clinical and Microbiological 
Effects of Non-Surgical Periodontal Therapy in Smokers and Non-Smokers. Journal of Clinical Periodontology, 25, 153-157. https://doi.org/10.1111/j.1600-051X.1998.tb02421.x

[25] Faddy, M.J., Cullinan, M.P., Palmer, J.E., Westerman, B. and Seymour, G.J. (2000) Ante-Dependence Modeling in a Longitudinal Study of Periodontal Disease: The Effect of Age, Gender, and Smoking Status. Journal of Periodontology, 71, 454-459. https://doi.org/10.1902/jop.2000.71.3.454

[26] Sheridan, P. (1987) Advances in Dental Research. The Journal of the American Dental Association, 115, 741-742.

[27] Albert, M., Banoczy, J. and Tamas, G. (1988) Dental and Oral Symptoms of Diabetes Mellitus. Community Dentistry and Oral Epidemiology, 16, 378-380. https://doi.org/10.1111/j.1600-0528.1988.tb00586.x

[28] Novaes, A.B., Pereira, A.L., Moraes, N. and Novaes, A.B. (1991) Manifestations of Insulin Dependent Diabetes Mellitus in the Periodontium of Young Brazilian Patients. Journal of Periodontology, 62, 116-122.

https://doi.org/10.1902/jop.1991.62.2.116

[29] Bridges, R.B., Anderson, J.W., Saxe, S.R., Gregory, K. and Bridges, S.R. (1996) Periodontal Status of Diabetic and Non-Diabetic Men: Effects of Smoking, Glycemic Control and Socioeconomic Factors. Journal of Periodontology, 67, 1185-1192. https://doi.org/10.1902/jop.1996.67.11.1185

[30] Eke, P.I., Dye, B.A., Wei, L., et al. (2015) Update on Prevalence of Periodontitis in Adults in the United States: NHANES 2009-2012. Journal of Periodontology, 86, 611-622. https://doi.org/10.1902/jop.2015.140520

[31] Nanaiah, K.P., Nagarathna, D.V. and Manjunath, N.K. (2013) Prevalence of Periodontitis among the Adolescents Aged 15-18 Years in Mangalore City: An Epidemiological and Microbiological Study. Journal of Indian Society of Periodontology, 17, 784-789. https://doi.org/10.4103/0972-124X.124507

[32] Aljehani, Y.A. (2014) Risk Factors of Periodontal Disease: Review of the Literature. International Journal of Dentistry, 14, 1-9. https://doi.org/10.1155/2014/182513

[33] Genco, R.J. (1996) Current View of Risk Factors for Periodontal Diseases. Journal of Periodontology, 67, 1041-1049.

[34] Van der Velden, U. (1984) Effect of Age on the Periodontium. Journal of Clinical Periodontology, 11, 281-294. https://doi.org/10.1111/j.1600-051X.1984.tb01325.x 